\title{
当前城市防洪工程建设和管理问题的探讨
}

\author{
杜亮 \\ 长春市双阳区城市防洪工程管理处 \\ DOI:10.18686/bd.v2i1.1189
}

[摘 要] 城市防洪工程作为城市经济与民生发展的基础保障, 是提高城市安全稳定的重要环节, 其很大程度的决定了城市 的发展水平。如今, 对城市防洪工程的概念理解已不单是修建堤坝, 防洪抗涝, 而应是顺应城市建设进度和发展步伐, 协调城 市基础生态环境,完善城市基础设施,提高城市景观面貌的系统性、综合性的工程。与此同时,过度重视基础建设,轻量管理的 传统城市建设理念随着时代的进步被摒弃,并逐步趋向建设与管理的双向发展。鉴于此,本文就当下城市防洪工程工作的发 展现状进行了研究, 并阐释了管理工作中存在的缺陷和不足, 同时提出了具有针对性的改善举措, 旨在可以为完善城市防洪 工程管理体系,推动城市的健康发展提供一些意见上的参考。

[关键词] 城市防洪; 工程建设;管理

结合实际工作经验可知,如今,防洪抗涝工作虽然相较 之前已有了长足的进步, 但其中仍存在诸多亟待解决的缺 陷和不足,所以需要我们加大治水工程的监管力度,严格遵 守国家法律规定,规范科学技术手段,注重防洪基础设施的 建设,加强资金与人力物力的支持,在对国家主体工程建设 的同时,高度关注防洪工程建设的实际工作,优化改进防洪 信息系统,提升预警系统的灵敏度,积极应用计算机技术和 电子信息技术, 创立具有先进科技水平的防洪抗涝工程体 系,保证管理工作的科学合理性和严谨性,这也是当下国家 机关单位以及业内相关人员所共同追求的目标。

1 以依法治水为原则, 加大防洪管理投入和工程建设 力度

如今, 国家在防洪抗涝工作方面制定并出台了相关的 法律法规, 其实质意义在于保障全国各地的防洪抗涝工作 能够严格遵守法律规定,并为其具体工作提供标准规范。同 时也是强制性的要求各地区在该项工作中要加强管理办法 的科学合理性。

首先,要严格监督制度的贯彻落实情况和执行效果。其 次, 在防洪抗港工作中, 要加强行政管理的专业性及适应性。 要完善防洪抗灾工作的基础设施建设, 提高行政执法水平, 加强管理办法的实效性。再者,创设符合现代发展观念的工 作流程,维系工作秩序的流畅稳定。开展工作时应遵守国家 法律条例规定和行业道德规范,加强河道防洪性能、山区防 洪基础建设、堤坝稳固性、水域密集区域的抗涝举措,对这 些易发生洪涝灾害的区域重点防治, 制定科学有效的治理 方案和紧急预案。定期开展形式多样性的防洪抗涝工作检 查,走访调查制度落实情况,建立区域性的专项立法,对非法 侵占河道、违法水利建设、擅自采砂挖地的行为严厉惩治, 不给不法分子以可乘之机, 切实维护人民群众的基本利益 不被破坏。

2 拓宽资金渠道,强化专款专用意识

首先,要调动社会各界的广泛关注,激发各阶层力量对
工作的支持, 以政府为核心,充分借助政府在防洪抗涝工程 上给予的政策和权限的扶持, 保证防洪抗涝工程的建设与 管理能够长期稳定高效的运行。

其次,加大城市水利工程的公共行为力度。调动各行业 领域的主观能动性、积极主动性,拓展资金的渠道来源,在保 证国家主渠道稳定的基础上，吸引社会各阶层的资金流入, 加大经济周转空间,进而保证基础建设进度的持续稳定。

第三,加大行政监管力度,深化专款专用意识。最近几年 以来,为顺应时代的发展要求,防洪抗涝工程体制改革已趋 向完善,并取得了不小的成就,在创新体制的影响下,城市防 洪抗港工程及水利工作得以稳固发展。在保证了专款专用 政策的基础上,要深化资金合理利用的意识观念,加强行政 管理手段的合理合法性, 为防洪工程的发展奠定坚实的后 备保障。

\section{3 加大规划宣传力度}

第一,保证防洪工程的具体规划内容的透明化,让社会 各界了解工程的目的,丰富防洪抗涝工程的宣传形式,使民 众对规划内容能够有充分的理解, 明示公众防洪抗涝工程 的重要性,强调其实质意义和价值。保证行业内部的自律性, 维系防洪规划的合理合法性,完善基础设施建设。

第二, 要坚持城市防洪规划的硬性要求。各级政府部 门、相关单位机构要明确权限与职责,在防洪规划工作中, 贯 彻落实科学发展观念,领导其流程,监督其机制, 检查其效 果。各级政府部门和机关单位要依法行事,工作过程严格遵 守国家法律及区域性管理办法条例, 为了达到顺利实施防 洪规划的目标, 对工程的建设和管理区域要进行行政许可 的办理,充分发挥法律的作用及价值, 最大限度的保障防洪 区域防洪工程的建设质量。

\section{4 加快人才培养步伐}

第一,要创新人才培养模式,引进防洪抗灾专业领域人 才, 储备后续人才,提高城市防洪抗涝工作的科技水平,保证 管理工作的高效性。 
第二,创新科学技术手段,拓展科技研发领域,创建集思 广益、灵活多变的学术环境,设立多样性的学术科目,争取在 防洪抗涝工作中寻求理论的突破,为实际工作贡献力量。

第三,加强软硬件设施的基础建设,构建具有专业设计 水准,规划管理水平较高的领导层,从根本上提高防洪抗涝 工作的整体水平。

\section{5 加强洪泛区域的基础建设}

首先对“洪泛区域”这一概念进行理解, 从字面意义上 来说就是易发生洪涝灾害的区域。结合科学试验及实际经 验可知,要想从根本上加强对该区域的治理,仅凭借传统的 强制管理措施是无法实现的, 尤其是对于非工程措施来说, 相关制度的落实情况就更加困难。第一,要对该区域内的基 础建筑加强管理,保证防洪物资的充足。要严格遵守高、宽、 轻重、易于搬迁否等指标,为防洪工作提供基本的保障,能够 保证在第一时间疏散人员,转移物资,降低自然灾害所造成 的损失。第二,在该区域内,开展政策允许的经济文化等活 动,创建合理的强制保障措施,例如保险购买等。也就是说, 在洪泛区域内所组织的团体性或个人活动, 依照实际目的 的界定,上缴相应的保险费用,充足防洪抗涝工作的后备资 金。第三,完善该区域内应急措施的基础设施建设。在该区 域内设立相应的警示标志, 明示重点区域与非重点区域, 应 急疏散通道和安全区域要格外醒目。同时,要配置充足的紧 急救护器械, 组织紧急救护团队, 检测预警器材的运行状态, 最大程度的保证人民群众的生命财产安全。第四,保障信息 系统的良好工作状态。在易发生洪涝灾害的区域内,配备性 能优良的预警设施,例如水文情况监测、降雨量预测、气候 环境变化监测、洪涝程度科学模拟、提拔性能监测等,完善 指挥决策信息和数据的真实性, 确保各项数据在安全数值 范围内,再公示群众,积极做好各项准备工作,有理有据,从而 有效减低洪涝灾害的损失。第五,洪灾发生后,第一时间送达 国家的救灾资金和国际援助款, 与此同时, 要积极调动社会 各界的力量,提倡捐款捐物。国家要对受灾区域的群众给予 资金补偿,并提供物力支持,保证灾区的重建工作有序进行, 尽快恢复生产生活, 维系公共活动灾后的调整, 为群众提供 基本的生活保障。

\section{6 升级防洪信息、预警系统建设确保防洪工作开展}

6.1 具体决策及预案深人群众

一是要加强区域内的宣传力度, 大力普及防洪抗涝基 础常识。二是加强洪泛区域内各行各业、广大群众防洪抗洪
预防演习,做到有备之而无不及。三是通过电视、广播、报 刊、网络及手机短信形式, 告知群众相关工作机制及人员组 成情况,公示预警信号、预警方式、转移路线等。

6.2 保证预警设施的良好性能

综合考量区域内的地理环境和基础建设情况, 分析并 确定洪泛区域的具体位置, 在派人至实地监测后发现存在 危险情况下,则应升级强化洪灾监测预警系统的建设。保证 监控设施的完善和严密性, 实时检测和收集各项地质及自 然环境变化数据,及时预警,保证洪灾发生后群众能够在第 一时间转移。

\section{7 加强洪泛区域闲置土地管理}

随着城市化建设规模的不断扩张, 土地资源的利用价 值逐步被重视。所以,应当实现对土地资源的统一规划, 统一 管理, 充分提高土地利用率。同时, 加强共泛区域内闲置土地 的管理,创造经济利益。

\section{1 合理利用闲置土地}

在符合国家相关规定的基础上，取得区域内土地管理 条例的许可, 严查单位及个人名义的乱挖乱建, 科学的规划 土地, 提高资源价值, 合理的利用闲置土地, 增大利用率, 为提 高城市国民经济总产值做贡献。

\section{2 改善区域环境建设}

要充分利用洪泛区域闲置土地、荒地、堤坝周围及防洪 抗洪工程周边区域,进行绿色植被的覆盖,扩大绿化面积,设 计符合景观特色的塑雕工艺品,美化围栏等,改善环境,创立 具有独特韵味的区域风景线。

\section{8 结语}

总而言之, 城市防洪工程是城市经济建设的基础保障, 更是维系城市安全的重要举措, 所以我们要在日常的建设 与管理工作中,强化管理意识,全面贯彻落实科学理念,综合 考量自身的发展情况,积极做好预警工作,制定合理预案,进 而保障人民生产生活的安全与稳定。

\section{参考文献:}

[1]倪晓峰,赵英.浅谈提升水利工程管理能力的技术改 进措施[J].水利建设与管理.2016,36(06):63-66.

[2]杨印.城市防洪工程运行管理的实践与思考[J].江 苏水利.2010(07):36-38.

[3] 隋晓红. 简析城市防洪水利工程的运行管理和建设 [J].科学技术创新,2017,(30):179-180. 